\title{
Educational guidance on water under the paradigm of complexity as a result of a comparative study between Spain and Mexico
}

\author{
José Gutierréz Pérez ${ }^{1}$ and Laura Galván Pérez ${ }^{1 a}$, \\ ${ }^{1}$ Department of Research Methodology and Diagnosis in Education. University of Granada. Faculty \\ of Education Science, Campus Cartuja, 18011, Granada
}

\begin{abstract}
This paper is intended to help lay the groundwork for the formulation and design of programs and materials for environmental education focused on water issues and based on the perspective of the new water culture and ecosystem services. The methodology is based on a study of the type of environmental education promoted in a sample of programs and resources whose focus is water: identifying under what paradigm is inserted, which models implicitly management supports them and if there is a mention explicitly to ecosystem services such as conceptual support a modern approach to the topic of study in two countries such as Spain and Mexico. As a result, a set of criteria and recommendations help to guide and reorient educational intervention programs are proposed interested in addressing water issues from more advanced conceptual approaches and new generation.
\end{abstract}

\section{Introduction}

\subsection{The topic and the problem}

From the perspective of reductionist paradigm, water is often considered as a simple resource to consume, managed as a kind of captive fluid under channeling, trade and commercialization. However, water is a much more complex, conceptually and functionally speaking element, either the place of its cycle in the regulation of the habitability of the planet, either by the heterogeneity of services provided to our civilization its presence in different aquatic ecosystems.

If we start from the idea of water as isolated and decontextualized natural element of the ecosystem, we are implicitly promoting a management model that puts the same resource itself at risk by ignoring its context. By depriving the ecosystem of considerable amounts of water without studying the possible implications and consequences in the global system and

\footnotetext{
${ }^{a}$ Corresponding author: lauragp@correo.ugr.es
} 
worsen their quality by poor or no purification, among other issues, we are degrading the ecosystem to the point of undermining the capacity thereof providing water and other basic services.

Aquatic ecosystems with other ecosystems are able to generate a number of services: service-supply from biotic and geotica (fresh water, timber, medicines); regulation service linked to good performance (climate, water, quality air, ...) and cultural service associated with intangible values of community (cultural identity, local knowledge, leisure and recreation), which depends on the maintenance of life on the planet and human welfare.

Manage water as a resource exclusively focused on human uses, it responds to an anthropocentric model to understand natural systems which involve ecosystem degradation, putting at risk not only the water, but also a number of basic services for community development of our peoples. For this it is essential to change the paradigm through which we look at the water to conceive not only as a resource, but as something much broader and complex as a dynamic system, such as aquatic ecosystem, endowed with complexity and interactions; and direct management to the perspective of integral ecosystem management, prioritizing the conservation of the structure and the proper functioning thereof, and including a holistic view in their management.

\subsection{Significance of the study}

We believe that most of the environmental education programs dealing with water are based on a reductionist paradigm, looking at water as a single stream, without understanding the water as an element that is part of a complex system called aquatic ecosystems. Therefore, it is necessary to reflect on how environmental education traditionally has focused the theme water and redirect this approach to more holistic and integrated new looks such as the new water culture and systemic eco services. The importance of the research is to determine for which model is working the water from environmental education in two countries of study such as Spain and Mexico, and raise new educational guidelines under the new prism.

\section{Methodology}

In order to establish the basis for the formulation of environmental education initiatives on water from the perspective of the new culture of water and ecosystem services it is to collect, analyze, study and evaluate a number of initiatives, programs and resources which make up the study sample. Among the research questions we include the following: a.) What are the characteristics of environmental education initiatives on water?; b.) which are the paradigms that support environmental education programs on water?; c.) which is the management model that promote environmental education programs on water? and d.) Do they make explicit mention about ecosystem services?

The sample includes those initiatives which work water issues form environmental education. For environmental education initiatives on water, we understand those different types of projects (programs, teaching materials, equipment, exhibitions, campaigns, etc), which may be developing the theme water in its many aspects, both formal, non-formal education, carried out by various public and private organizations.

The sample has been classified according to the following types of initiatives: teaching material; environmental communication program; audio-visual material; teaching exhibition; program of visits outdoors; environmental education campaigns; programs of social participation; volunteer programs in rivers and environmental Equipment.

In each of these types is selected the following initiative: 


\subsection{Analysis categories}

The following categorization allow to study, analyze and evaluate the initiatives of the sample to frame in a reductionist paradigm or complex, using different thematic indicators in each of the categories designed, which are as follows.

- Category 1. Discursive model: conceptions about water and the value of each of the indicators, which are detailed below. Hydraulic perception (value 0), hydrological perception (value 1), eco systemic perception (value 2) and perception of a new culture of water (value 3), and indicators are: 1. Availability; Indicator 2. Resource / right; Indicator 3. Simplicity / complexity; Indicator 4. Management Model.

- Category 2. Explanatory model: teaching and learning models. The value set for each of the indicators in relation to constructivism and complexity, is as follows: None (0), Something (value 1), medium (2) and quite (3), and indicators are: Indicator 6. Simplicity / complexity; Indicator 7. Constructivism; Indicator 8. Dealing with conflicts; Indicator 9. The Language.

\section{Results}

\subsection{Case Study: Spain}

In the following chart we can see the score of each of the initiatives in relation to the discursive model (hydraulic, hydrologic, eco systemic and holistic) and the explanatory model (none, some, medium, quite in related to constructivism) which we described above (figure 1), as well as the paradigm in which they belong: reductionist, in transition, weak complexity and strong complexity (figure 2 and 3). By other hand, we show in more detail the analysis of the initiatives in relation to the management model (hydraulic, in transition and holistic model) in figure 4 and the reference to ecosystem services (explicit, implicit, and it makes no mention) in figure 5.



Figure 1. Discursive and explanatory model

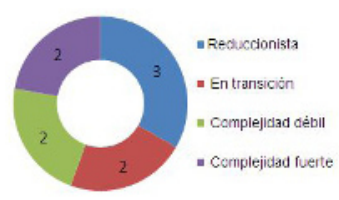

Figure 3. Paradigm of the initiatives

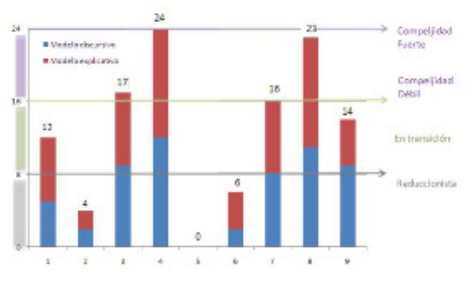

Figure 2 Analysis of the paradigm

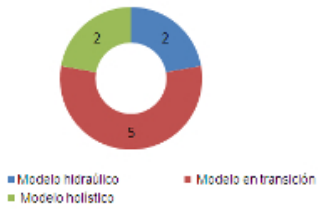

Figure 4. Management model



Figure 5. Ecosystem services 


\subsection{Case Study: Mexico}

In the following chart we can see the score of each of the initiatives in relation to the discursive model (hydraulic, hydrologic, eco systemic and holistic) and the explanatory model (none, some, medium, quite in related to constructivism), which we described above (figure 6), as well as the paradigm in which they belong: reductionist, in transition, weak complexity and strong complexity (figure 7 and 8). By other hand, we show in more detail the analysis of the initiatives in relation to the management model (hydraulic, in transition and holistic model) in figure 9 and the reference to ecosystem services (explicit, implicit, and it makes no mention) in figure 10.

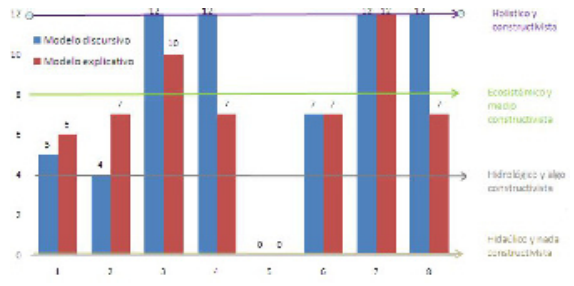

Figure 6. Discursive and explanatory model

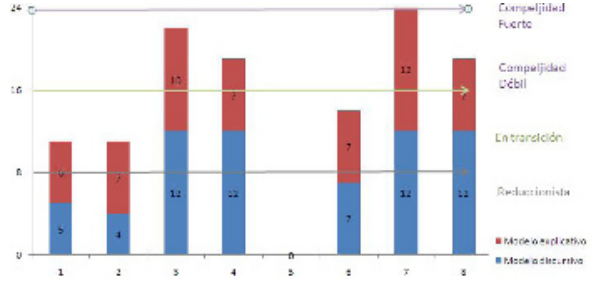

Figure 7 Analysis of the paradigm



Figure 8. Paradigm

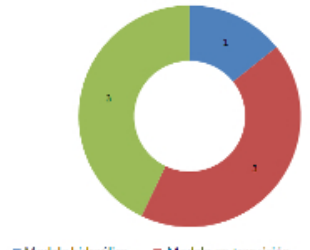

Figure 9. Management model

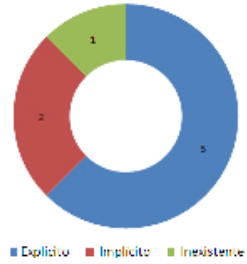

Figure 10. Ecosystem services

\section{Conclusion}

\subsection{Case Study: Spain}

After analyzing each of the initiatives we have three separate initiatives are around the reductionist paradigm two initiatives are in the reductionist paradigm but transition to the paradigm of complexity, two initiatives are in a paradigm of weak complexity and partial, and two initiatives are in a true paradigm of complexity. In total, we would have five initiatives in the reductionist paradigm, and 4 initiatives in a paradigm of complexity.

\subsection{Case Study: Mexico}

A detailed analysis shows that one initiative is about the reductionist paradigm two initiatives are in the reductionist paradigm but transition to the paradigm of complexity, two initiatives are in a paradigm of weak and partial complex, and 2 initiatives situated in a real paradigm of complexity. In a comprehensive analysis, we see that four initiatives are in the reductionist paradigm, and 4 initiatives in a paradigm of complexity. 


\subsection{Overall conclusions}

Both in the case study of Spain and Mexico, the analysis of the data show many similarities in how water issues are addressed in the environmental education initiatives. If we average about 8 initiatives, which will place, about 4 in the reductionist paradigm and another 4 in the paradigm of complexity, it would seem that we are halfway to close initiatives to build new water culture and services ecosystem, as well as being able to incorporate the paradigm of complexity and constructivist learning. However, if we stop to analyze the data in detail, we see important nuances that make us rethink the concept of how to address the complexity of environmental education initiatives on water.

In short, it is perceived complicated to be able to make this transition and build that complexity, for which we must stop slowly in what factors determine a look complexity including new water culture and systemic eco services.

Then we devised a series of recommendations on how to build a perception of water under both perspectives and what criteria or lines of suggestions should be taken into account to choose a constructive and complex methodology that facilitates or permits include those eyes, and these are useful both in the case of Spain and Mexico.

\subsection{Educational Guidance}

\subsubsection{Discursive Model}

If we want to make a construction around water from the perspective of the new culture of water and ecosystem services we should include a set of concepts, visions and themes in our environmental education programs on water, such as:

Transmit the water availability depending on the weather, the ecological state of ecosystems and according to the needs and social agreements concluded in the given territory, with a culture and ethical issue inclusive look.

Make visible the interrelationship and interdependence between aquatic ecosystems and social ecosystem, and show how depending on which relationship is established on the basis of the management model and culture around these ecosystems, they can help or harm our human welfare

Introduce water as a human right (access to clean water and sanitation, food sovereignty and personal care and hygiene) compared to water as an economic resource exclusivity (private interest over the public interest) through participatory governance.

A management of aquatic ecosystems to assess ecosystem services through ecological status of ecosystems with an inclusive culture and ethics in each region and society look to jointly build a common dialogue and a new culture around water and these ecosystems that allow the maintenance of biodiversity and our human being.

\subsubsection{Explanatory model}

Regarding how to transmit, teach and internalize these conceptions and visions from the new water culture and ecosystem services should include constructivist methodology under the paradigm of complexity. Some guidelines for environmental education programs on water are:

Use a remote language hydrological perspective and the dominant paradigm raised in the mainstream media to create a new dialogue and a new culture in relation to socially owned water and our aquatic ecosystems. 
Generate conditions that encourage individual and group reflection on ethical conflicts allowing positioning, building a common dialogue on water for solving problems, fostering creativity throughout the process, and especially for the preparation of proposals.

Communicate water issues around processes and relationships, not only associated with data and facts, being able to consider some linear relationships between more than two elements to move on to consider a greater number of elements that draw chain relationships in some so a more complex system.

Being able to create a picture of the water with many diverse elements.

\section{References}

1. Aguilera, F., Towards a new water economy: Key issues. Iberian Congress on Water Management and Planning. December 14 to 18, Zaragoza, Spain (1998)

2. Arrojo, P., The ethical challenge of the new water culture: functions, values and rights game. Edt. Polity Press. Barcelona, Spain (2005)

3. Arrojo, P., The public and private sectors in water management. Iberian Congress on Water Management and Planning. December 5 to 7, Lisbon, Portugal (2013)

4. Berga, L., Dams and reservoirs in the twentieth century Spain. Public magazine, Works 2003, No. 3438, 37-40 (2003)

5. Coixet, I. "Aral. Lost Sea ". Documentary. http://www.wearewater.org/es/aral-el-marperdido 1900. September, 2010.

6. Diaz, M., Spanish evolving water policies since the Enlightenment until today. Iberian Congress on Water Management and Planning. Zaragoza, Spain (1998)

7. Estevan, A., Inheritances and problems of the Spanish water policy. Bilbao, Spain: Bakeaz (2008)

8. Fernádez, J.R., The Anthropocene: the ecological crisis is global. Madrid, Spain: Virus.

9. New Water Culture Foundation. 2014. What is the meaning waterworks? Guide to the New Water Culture, Zaragoza. Spain. Available in: http://www.fnca.eu/guia-nuevacultura-del-agua/ (2011)

10. Garcia, J. E., Environmental education, constructivism and complexity. Sevilla: Diada Editorial S.L (2004)

11. Garcia, J. E., The contents of the Environmental Education: a reflection from the perspective of complexity. Research journal at school, No. 53, 31-53 (2004)

12. Martinez F. J. and Antoranz $\mathrm{M}^{\mathrm{a}}$.A., "Water and the Spanish education system." The Water Framework Directive: realities and futures. III Iberian Congress on Water Management and Planning. November 13 to 17, Seville, Spain (2002)

13. Yaguas, G., Environmental profile of Spain, 2013 Report based on indicators. Ministry of Environment. http://www.magrama.gob.es/es/calidad-y-evaluacionambiental/publicaciones/Perfil_Ambiental_2013 tcm7-357526.pdf (2013)

14. Montes, C. Torres, I. Santos, F., Benayas, J., Gutierrez, V., Gamo, D., et al., 2011. Ecosystems and biodiversity for human well-being. Assessment Millennium Ecosystem of Spain. Summary of results. Biodiversity Foundation and Autonomous University of Madrid. Madrid, Spain.

15. United Nations., 2nd United Nations report on the development of water resources in the world. Water, a shared responsibility (2006)

16. United Nations., 3rd United Nations report on the development of water resources in the world. Water in a changing world (2009)

17. United Nations., 3rd United Nations report on the development of water resources in the world. Water management in a context of uncertainty and risk (2012)

18. Novo, M., Environmental education in times of crisis. Trasánlatica education. No. 9: 6$13(2011)$ 
19. Garment, J., Critical analysis of the Water Framework Directive. Technical Seminar: Application of the DMA before 2015. University of Huelva (2013)

20. Roca, F., Reflections on the first water planning process of the WFD in Spain. Observatory of the Water Framework Directive. New Water Culture Foundation (2013)

21. Steffen, W, Wendy Broadgate, Lisa Deutsch, Owen Gaffney, and Cornelia Ludwig. The trajectory of the Anthropocene: The Great Acceleration.

22. The Anthropocene Review, January, 2011.

23. Yann Arthus-Bertrand. Home movie script. June, 2005. http://www.saber.ula.ve/bitstream/123456789/29554/3/latierra_nuestro_hogar.pdf

24. WWF., Living Planet Report. Biodiversity, biocapacity and future proposals (2012) 